\title{
An Ethical-Legal Analysis of Medical Assistance IN DYING FOR THOSE WITH MENTAL ILLNESS
}

\author{
RYAN TANNER ${ }^{*}$
}

\begin{abstract}
This article considers sources of opposition to allowing access to medical assistance in dying for individuals with mental illness. It originated with an observation by members of the University of Toronto Joint Centre for Bioethics that in mainstream Canadian culture - as well as in political, academic, and professional circles — such opposition remains widespread (and often reflexive). This opposition exists even in light of broad support for access to assisted dying for individuals with illness manifesting in physical suffering. Most Canadians treat the prospect of assisted dying for those with mental illness with suspicion, and it is worth exploring why this opposition persists, what arguments can be leveled to support it, and whether those arguments can be sustained. To that end, I identify five objections to assisted dying for the mentally ill that seem to characterize the public debate, and argue that none are sustainable. They either rely on false premises or otherwise fail to secure the conclusion that assisted dying should be off limits to people suffering from mental illness, even when such mental illness is their sole underlying condition.
\end{abstract}

\section{TABLE OF CONTENTS}

I. INTRODUCTION . . . . . . . . . . . . . . . . . . . . . . . . . . . 149

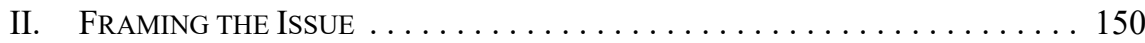



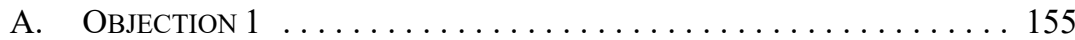

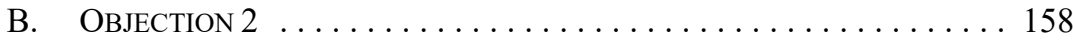

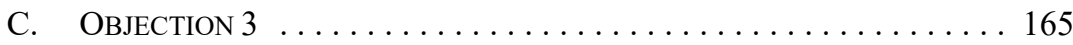

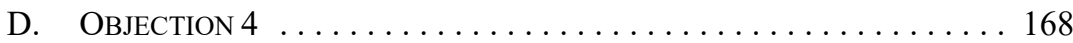

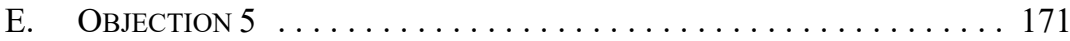



\section{INTRODUCTION}

In its 2015 decision in Carter v. Canada, the Supreme Court of Canada found that the Criminal Code ban on medical assistance in dying (MAID) violated section 7 of the Canadian Charter of Rights and Freedoms, and struck down the ban. ${ }^{1}$ The federal government responded the following year by enacting Bill C-14, ${ }^{2}$ amending the Criminal Code to permit and regulate medical assistance in dying for competent, consenting individuals with a grievous and irremediable medical condition. ${ }^{3}$ While most Canadians support the move to legalize assisted dying, ${ }^{4}$ debate persists over whether the law extends far enough. Many believe that the legislation is too restrictive because it does not permit

$\mathrm{PhD}$, JD, member of the University of Toronto Joint Centre for Bioethics Task Force on Medical Assistance in Dying.

Carter v Canada (Attorney General), 2015 SCC 5 [Carter].

An Act to amend the Criminal Code and to make related amendments to other Acts (medical assistance in dying), 1st Sess, 42nd Parl, 2016 (assented to 17 June 2016), SC 2016, c 3 [Bill C-14].

Carter, supra note 1 at para 127.

An Angus Reid poll published in 2016 found that 90 percent of Canadians think some form of assisted death should be allowed: see "Physician-Assisted Suicide: Canadians Reject Certain Commons Committee Recommendations" (1 April 2016), online: Angus Reid Institute < angusreid.org/assistedsuicide-law/> [Angus Reid]. 
access to MAID for persons whose natural death is not already "reasonably foreseeable." It thereby precludes access for individuals who may be undergoing considerable suffering, and who wish for their lives to end, but whose anticipated deaths are remote. The discussion here pertains to a subset of these individuals, whose sole underlying medical condition is psychiatric in nature, who wish to see their lives end, but whose deaths are not reasonably foreseeable in the way contemplated by the law. Should access to MAID be extended to these individuals? The federal government has commissioned a review of this issue under the auspices of the Council of Canadian Academies, ${ }^{6}$ and my purpose here is to explore what I take to be the main sources of opposition to extending access to these patients. I argue that the relevant objections fail, and conclude that under certain conditions MAID should be accessible to individuals with mental illness, even where mental illness is their sole underlying condition and where their deaths are not "reasonably foreseeable."

\section{FRAMing THE ISSUE}

Assisted dying is often conceived as a form of suicide, and while that conception is probably a mistake, ${ }^{7}$ both are characterized by decisions and actions a person takes to secure their own death. It is therefore unsurprising that considerations pertaining to suicide are often applied (correctly or incorrectly) in the context of assisted dying. For example, one perception that still haunts thinking on assisted dying, particularly where mental illness is involved, is that suicidality is always a symptom of some mental defect or failure of reasoning. When this perception gets extended to any decision to end one's life, it naturally follows that "there can be no such thing as a competent desire to die." ${ }^{8}$ If correct, this would mean allowing access to assisted dying is a mistake in any event, since any decision to pursue assisted dying would be irrational or non-voluntary — a product of defective thinking. The perception may have many sources, including considerations involving the "sanctity of life" (for example, that nothing is more important than life itself), or the extreme badness and

5 Criminal Code, RSC 1985, c C-46, ss 241.2(1)(c), 241.2(2)(d). Specifically, section 241.2(2)(d) requires that the person's "natural death has become reasonably foreseeable, taking into account all of their medical circumstances, without a prognosis necessarily having been made as to the specific length of time that they have remaining."

"Medical Assistance in Dying," online: Council of Canadian Academies <scienceadvice.ca/en/assess ments/in-progress/medical-assistance-dying.aspx $>$. The mandate to conduct this review was part of Bill C-14 itself (supra note 2, cl 9.1(1)). Also included were mandates to review requests by mature minors, and advance requests.

Applying the language of "suicide" in the context of assisted dying is regarded in many circles not just as a mere conceptual mistake, but also as a source of bias because of the negative associations attendant with suicide proper. For example, André Picard writes, "[s]uicide is an act of self-harm that is almost always a byproduct of mental illness like schizophrenia or severe depression. This is in no way comparable to hastening death via a methodical, sober process with a number of legal safeguards. Calling medically assisted dying suicide is a lot like calling surgery a knife attack" (André Picard, "The Importance of Picking a Vocabulary for Dying," The Globe and Mail (18 June 2012), online: $<$ https://www.theglobeandmail.com/news/politics/the-importance-of-picking-a-vocabulary-fordying/article4338418/>). For contrast, consider John Maher's remarks in the context of MAID for those with mental illness as the sole underlying condition, in "What Troubles Me as a Psychiatrist About the Physician Assisted Suicide Debate in Canada" (2017) 10 J Ethics in Mental Health at 1, online: $<$ https://www.jemh.ca/issues/v9/documents/JEMH-final-Editorial-iii.pdf $>$ [Maher, "What Troubles $\mathrm{Me}$ ']:

The term "MAID" is misleading when applied to persons whose sole underlying condition is a mental illness. They are not dying. Natural death is not "reasonably foreseeable". They are not "terminally ill" on any usual definition of terminal illness (e.g. the physical illness is causing death; death will occur in under six months). The proper terms when considering this population are "suicide", "assisted suicide", and "physician assisted suicide".

$8 \quad$ Susan Stefan, Rational Suicide, Irrational Laws: Examining Current Approaches to Suicide in Policy and Law (New York: Oxford University Press, 2016) at 31 [footnote omitted]. 
permanence of death (rationally outweighing any motivations to end one's life), or the perception that suicidality is transient and there are always better solutions to one's problems. Among health professionals, the perception has roots in the correlation of suicide with mental illness and the extreme caution with which the professionals approach such patients and their interest in remedying their mental health. ${ }^{9}$ Psychiatrists are particularly likely to regard suicidal desires as a symptom of a disorder, largely because they are trained to prevent suicides, ${ }^{10}$ and because their clinical experience informs their posture toward suicidal thinking: they often encounter cases where suicidal ideation has been successfully addressed through various forms of treatment. Further, the practice of psychiatry is deeply embedded in a "recovery model" in which mental illness is regarded as remediable, so suicidal desires tend to be implicitly regarded as treatable symptoms rather than the product of a rational assessment. ${ }^{11}$ Suicidal behaviour is regarded as dysfunctional by definition. ${ }^{12}$

Though common, the perception that there is no such thing as a competent desire to die is almost certainly mistaken. Even if assisted dying is properly conceived as a form of suicide, there is still little reason to believe that all suicides are either irrational or the result of defective thinking. Most Canadians seem to agree on this score, since most of them support the proposition that medical assistance in dying should be accessible in at least some circumstances, ${ }^{13}$ and the current law in Canada reflects this. We can also see this in the fact that decisions to forego medical treatment or other life sustaining measures are generally respected and not subject to this kind of criticism, even though such decisions can be just as effective in securing an early death as suicide. It takes a great deal of work to argue that opting for an early death through withdrawal of treatment can be rational while opting for suicide is not, given comparable circumstances.

Additionally, the law has historically assumed that at least some suicides are rational. For instance, when suicide was still criminalized, the law allowed for an exception where the individual was found to be insane. For a suicide to be a crime, it required that the accused had a sound mind; compos mentis was considered an element of the offense. ${ }^{14}$ Susan Stefan

See Thomas S Zaubler \& Mark D Sullivan, "Psychiatry and Physician-Assisted Suicide" (1996) 19:3 Psychiatric Clinics North America 413 at 414-15 [footnotes omitted]:

The belief that suicidal ideation is a sign of psychopathology stems from the high correlation between suicide and mental illness.... Many psychiatrists ... have traditionally believed that a request for death ... cannot represent a rational decision. By treating the mental illness, the conventional wisdom goes, rationality is restored and the patient will no longer have a desire for death.... Psychiatrists ... [insist] that suicidality among such patients is treatable, preventable, and certainly a sign of psychiatric disorder.

Maher, "What Troubles Me," supra note 7 at 4:

That some psychiatrists in Europe are actually involved in not just the process but also the act of assisted suicide for persons with mental illness (injecting the lethal drugs themselves) is profoundly disturbing to me. My vocation as a psychiatrist entails the exercise of certain virtues and discipline specific expertise. A neurosurgeon removes brain tumors with aplomb. I help people make meaning of their suffering and find hope and purpose no matter what their life circumstances. Both specialists will fail from time to time, but our job and goal are clear. Just as the Pope should not perform abortions, and the Dalai Lama should not take up arms, a psychiatrist should not counsel or abet suicide, for in doing so I have misunderstood and betrayed my vocation and profession. 
discusses the legal history of suicide at length in her book Rational Suicide, Irrational Laws: Examining Current Approaches to Suicide in Policy and Law, and summarizes in this way:

[O]ne clear and basic consistency does emerge. The law has always assumed that people are legally responsible for their suicides and suicide attempts, and the burden of proof lies with those who claim that a person who committed suicide was not responsible, competent, or sane. The name of this exception has varied over time, and across different areas of law, but the fundamental truth — that the vast majority of suicidal people are competent in the eyes of the law - has never changed. Attempting or completing suicide has never, in and of itself, been sufficient in any branch of law to determine that an individual was incompetent or lacked capacity. ${ }^{15}$

Given the above, I will assume from here on that a decision to end one's own life can be genuine in the sense that it is an authentic expression of one's rational will, without necessarily being the product of irrationality or an otherwise unsound mind.

Arguments in favour of access to medical assistance in dying have usually focused on those who are suffering from a terminal illness. In this respect, Canada's legislation is permissive ${ }^{16}$ in that it does not require that an individual have a terminal illness per se in order to access MAID, but only that their death has become reasonably foreseeable. ${ }^{17}$ What, exactly, counts as a reasonably foreseeable natural death under the law remains controversial, and an extensive forthcoming analysis conducted by Jocelyn Downie and Kate Scallion concludes that no interpretation "can be shown to be consistent with all of the rules of statutory interpretation and all of the expressions of legislative intent." ${ }^{18}$ Elsewhere, Downie and Jennifer Chandler have argued that the most satisfactory interpretation is that a reasonably foreseeable natural death is one that must be reasonably anticipated to occur by one of a range of predictable ways, or within a period of time that is not too remote; thus the

15 Ibid at 12-13. Stefan provides specific examples of situations where the law assumes those who commit suicide can be competent at 9-10 [footnotes omitted]:

Four states have legalized assisted suicide, underscoring the default assumption that terminally ill people who want to end their lives are presumed competent unless determined otherwise. But there is more: we permit competent suicidal death row prisoners to abandon appeals that might well save their lives and will certainly delay their deaths. Insurance law contains hundreds, if not thousands, of decisions, including many Supreme Court decisions, distinguishing "sane" suicides from "insane" suicides for purposes of life insurance.

16 The assisted dying regimes operating in American states such as Oregon and Washington require patients to have a prognosis for survival of six months or less in order to access assisted dying. The European regimes in the Netherlands, Belgium, and Luxembourg have no comparable restriction and do not require a patient to be terminally ill: see Ezekiel J Emanuel et al, "Attitudes and Practices of Euthanasia and Physician-Assisted Suicide in the United States, Canada, and Europe" (2016) 316:1 J American Medical Assoc 79 at 80.

17 Criminal Code, supra note 5, s 241.2(2)(d). The reasonable foreseeability criterion remains in place for now, but it may be short-lived. The criterion (among other things) is a subject of ongoing Charter litigation, and importantly, the Supreme Court did not endorse the reasonable foreseeability criterion in Carter, supra note 1. See Lamb v Canada (AG) (27 June 2016), Vancouver, BCSC S-165851 (Notice of Civil Claim), online: <https://bccla.org/wp-content/uploads/2016/06/2016-06-27-Notice-of-CivilClaim-1.pdf>; Truchon c Canada (AG) (13 June 2017), Montreal, Que CS civ 500-17-099199-177 (Notice of Application to Proceed for Declaratory Relief), online: <eol.law.dal.ca/wp-content/ uploads $/ 2017 / 06 /$ demande-introductive-da $\% \mathrm{C} 2 \% 80 \% \mathrm{C} 2 \% 99$ instance-en-jugement-dA $\% \mathrm{CC} \%$ $83 \% \mathrm{C} 2 \% 89$ claratoire. pdf $>$. For an argument that the more restrictive elements of Bill C-14 can be reconciled with the Carter decision after all, including the reasonable foreseeability criterion, see Trudo Lemmens, Heesoo Kim \& Elizabeth Kurz, "Why Canada's Medical Assistance in Dying Legislation Should be C(h)arter Compliant and What it May Help to Avoid" (2018) 11:1 McGill JL \& Health S61 at S100-19.

18 Jocelyn Downie \& Kate Scallion, "Foreseeably Unclear: The Meaning of the 'Reasonably Foreseeable' Criterion for Access to Medical Assistance in Dying in Canada," Dal LJ [forthcoming], online: Social Sciences Research Network<https://papers.ssrn.com/sol3/papers.cfm?abstract_id=3126871>. 
"criterion will be satisfied by either temporal proximity ('a period of time that is not too remote') or a predictable cause of natural death, and neither is a necessary condition if the other is present." 19

Whatever legal interpretation is ultimately settled upon, it is sufficient here to simply acknowledge that to satisfy the reasonable foreseeability criterion an individual must be dying in a sense somewhat more robust than that which applies to all of us all the time, ${ }^{20}$ even if it does not require that an individual have a terminal illness. ${ }^{21}$

One might be inclined to think that adding the reasonable foreseeability criterion was intended, at least in part, to exclude individuals with mental illness as their sole underlying condition, particularly given the dim view the public seems to take of their prospective eligibility. ${ }^{22}$ Indeed, the government itself has sometimes interpreted the legislation this way, ${ }^{23}$ but it is important to note that there seem to exist extreme cases where an individual might satisfy the reasonable foreseeability criterion while suffering from a mental illness as their sole underlying condition - for example, sufficiently advanced cases of anorexia nervosa ${ }^{24}$ Consider also that mental illness is associated not only with increased suicide risk, but that it also can impact physical well-being and self-care. For example, people with mental illness often do not seek medical attention for worrisome symptoms until it is too late. ${ }^{25}$ But even acknowledging all of this, it remains the case that the current law has the

19 Jocelyn Downie \& Jennifer A Chandler, "Interpreting Canada's Medical Assistance in Dying Legislation" (Montreal: IRPP, 2018) at 13-14, online: Institute for Research on Public Policy <irpp.org/wp-content/uploads/2018/03/Interpreting-Canadas-Medical-Assistance-in-Dying-LegislationMAiD.pdf $>$ [emphasis in original]. See also Jocelyn Downie \& Justine Dembo, "Medical Assistance in Dying and Mental Illness Under the New Canadian Law" (2016) 9 J Ethics in Mental Health, online: $<$ https://www.jemh.ca/issues/vp/documents/JEMH Open Volume Benchmark Medical Assistance in_Dying_and_Mental_Illness_Under_the_New_Canadiān_Law-Nov2016.pdf $\overline{\mathrm{S}}$.

20 Downie \& Scallion, supra note $\overline{1} 8$ [footnotes omitted] [emphasis in original]:

Clearly, it is not reasonable to interpret the legislation as meaning "that it is in accordance with reason/not absurd that health care providers are aware that someone will die a natural death" natural death is over 90 percent certain for all of us from the moment of our birth as fewer than 10 percent of deaths are a result of suicide, homicide, or accident. Therefore, the ordinary meaning of this phrase, read alone or in isolation, cannot provide a definition for this provision in the Act because doing so would violate the absurdity principle of statutory interpretation and the rule against "mere surplusage" (meaninglessness).

21 This is consistent with Justice Perrell's interpretation of the Criminal Code, supra note 5, s 241.2(2)(d) requirement that "natural death has become reasonably foreseeable, taking into account all of their medical circumstances, without a prognosis necessarily having been made as to the specific length of time that they have remaining," in AB v Canada (Attorney General), 2017 ONSC 3759 at Schedule A. Perrell writes at para 81 that, "[ $\mathrm{t}]$ he language reveals that the natural death need not be connected to a particular terminal disease or condition and rather is connected to all of a particular person's medical circumstances."

Angus Reid, supra note 4.

Downie \& Chandler, supra note 19 at 30-31; Downie \& Dembo, supra note 19 at 3.

Downie \& Dembo, ibid at 6.

As Marc De Hert et al, "Physical Illness in Patients with Severe Mental Disorders. I. Prevalence, Impact of Medications and Disparities in Health Care" (2011) 10:1 World Psychiatry 52 at 52 [footnotes omitted] reports:

A number of reviews and studies have shown that people with severe mental illness (SMI), including schizophrenia, bipolar disorder, schizoaffective disorder and major depressive disorder, have an excess mortality, being two or three times as high as that in the general population.... This mortality gap [translates] to a 13-30 year shortened life expectancy in SMI patients.

Statistics like these press the conclusion that mental illness can impose a "reasonably foreseeable" death, and that the window for successful treatment is not as indefinite as we might think. 
effect of excluding access for anyone who is not nearing death, and this will include most cases where mental illness is the sole underlying condition. ${ }^{26}$

Other criteria for eligibility in Canada are that the individual must be 18 years of age, capable of making medical decisions, and that the request for MAID must be voluntary and given with informed consent. ${ }^{27}$ These types of restrictions are similar in kind to those adopted in other jurisdictions where assisted dying is legal, and reflect a cautious approach to the issue of capacity: to be sure that the individuals who opt for an assisted death are making a decision that authentically reflects their own interests and desires. Which methods are preferable for assessing capacity is controversial, but the underlying rationale for these restrictions is to filter out cases where the individual's choice might not be voluntary or genuine, say, because of external pressure to opt for assisted dying, or because of cognitive distortions which result from mental illnesses such as depression.

This rationale is typically cashed out in terms of concern for the "vulnerable," an approach explicitly taken by the Supreme Court in Carter, as well as in Bill C-14. Bill C-14 characterizes the vulnerable as individuals who might be "induced, in moments of weakness, to end their lives" and who need "protection" from making a choice for assisted dying involuntarily. ${ }^{28}$ Precisely who counts as vulnerable is rarely defined in detail, but is standardly taken to include the elderly, disabled, and the mentally ill — individuals who are suspected to be particularly susceptible to external pressure or unsound decision-making in respect of MAID. Given the gravity and permanence of the decision to terminate one's life early, we want to be sure that the people opting to do so are doing so freely, and after clearheaded consideration.

While most Canadians agree that MAID should be allowed in some circumstances, whether and to what extent individuals with mental illness should be able to access it is much more controversial. ${ }^{29}$ The explanation for this greater controversy is easy to see: mental illness can threaten an individual's capacity to make decisions that genuinely reflect their interests. Suicidal ideation, for example, is a common symptom of depression, ${ }^{30}$ and even if we accept that not all suicides are irrational or pathological (that is, we reject the "no rational suicides" thesis), the presence or suspicion of mental illness throws into question our ability to access a patient's genuine preferences. These considerations underlie several different objections to extending MAID to the mentally ill explored below, but one more curiosity is worth mentioning before proceeding. The main concern here is whether someone with

26 One interesting thing to note is that in Carter, supra note 1 at para 111, the Supreme Court of Canada itself appears to suggest that "persons with psychiatric disorders" would not fall within the parameters for eligibility that the Supreme Court itself set down. Despite that comment, it still appears that the test formulated by the Supreme Court "leaves open the possibility that it would be unconstitutional to bar a capable adult from making the fundamentally important and personal medical decision that he or she can no longer tolerate the irremediable suffering of a treatment-resistant, severe mental illness" (Barbara Walker-Renshaw \& Margot Finley, "Carter v. Canada (Attorney General): Will the Supreme Court of Canada's Decision on Physician-Assisted Death Apply to Persons Suffering from Severe Mental Illness?" (2015) $9 \mathrm{~J}$ Ethics in Mental Health at 5, online: <https://www.jemh.ca/issues/v9/documents/ JEMH_Open-Volume_Benchmark_Assisted\%20Death-Nov20-2015.pdf $>$ ).

Crimină Code, supra note 5, s 241.2(1).

Bill C-14, supra note 2, Preamble. See also Criminal Code, supra note 5, s 241.2(1)(d).

Angus Reid, supra note 4.

Michael F Gliatto \& Anil K Rai, "Evaluation and Treatment of Patients with Suicidal Ideation" (1999) 59:6 American Family Physician 1500, online: <https://www.aafp.org/afp/1999/0315/p1500.html>. 
mental illness should be eligible to access assisted dying even if they do not have some other illness, that is, where mental illness is their sole underlying condition. But it is easy to see that mental illness will also (or at least seems to) complicate the issue of access to MAID even where it appears as a comorbidity with some other grievous irremediable (physical) illness. Cases of comorbidity are common because advanced physical illness is correlated with high rates of depression. For instance, about 40 percent of terminal cancer patients experience depression at some point. ${ }^{31}$ Most of the objections pertaining to mental illness explored below ought to function in the context of both types of case, even though comorbidity cases seem to receive much less attention. After all, if mental illness is a threat to a patient's decisional capacity, it remains a threat whether or not it is paired with some other illness or condition. The point is this: if we can demonstrate that otherwise healthy individuals suffering from refractory mental illness should sometimes be eligible for assisted dying, we will also have shown that patients suffering from both physical and mental illness simultaneously should sometimes be eligible as well. The more general question of whether and to what extent any individual with mental illness should be able to access MAID can be answered without reference to the role that physical illness might play in the decision. Thus it is only necessary to focus on "sole underlying condition" cases. Refractory depression is used as the main example. ${ }^{32}$

The five objections explored below are perhaps better characterized as "sources of opposition," since they each are stated in very general terms, and represent broad categories of more specific objections. The purpose here, though, is to set out and assess the general reasons for opposing access to MAID for people with mental illness that characterize the current debate, and it is appropriate to do that in general terms. Let us examine each objection in turn.

\section{OBJECTIONS}

\section{A. OBJECTION 1}

There are good reasons for restricting access to MAID for those who are not nearing death, including the considerable majority of patients who have a mental illness as their sole underlying condition.

At first glance, it seems like this objection should operate the same way for cases involving any irremediable condition that causes intolerable suffering where death is not reasonably foreseeable, whether the condition is physical or psychiatric. Canadians, however, tend not to see it that way. Almost three quarters of respondents to an Angus Reid poll

31 Donald L Rosenstein, "Depression and End-of-Life Care for Patients with Cancer" (2011) 13:1 Dialogues in Clinical Neuroscience 101. See also M Lloyd-Williams \& T Friedman, "Depression in Palliative Care Patients - A Prospective Study” (2001) 10:4 European J Cancer Care 270.

32 One problem with proceeding this way is that focusing on depression obscures important differences with and among other mental health diagnoses. Things like borderline personality disorder, conversion disorder, anorexia nervosa, and others all have unique features that merit exploration and which a focus on depression fails to capture. However, the purpose here is the narrow project of evaluating whether some mentally ill patients should be able to access MAID, and depression is (for better or worse) the diagnosis that is most often referenced in this connection; I will proceed this way for simplicity's sake. Further, insofar as other forms of mental illness present refractory intolerable symptoms, the arguments here can, as appropriate, be extended to cover them as well. 
conducted in 2016 said MAID should be allowed for non-terminal patients who are in a great deal of pain - approximately the same number who agreed that MAID should be available to the terminally ill. But when asked about psychological suffering, almost 80 percent said it was not sufficient grounds for allowing individuals to access MAID. ${ }^{33}$ This suggests that people regard psychological suffering as somehow different or less urgent than physical suffering. ${ }^{34}$ Whether there is such a difference is explored below. Setting that issue aside for the moment, it is worth examining whether there are any good reasons for restricting MAID to dying patients in the first place. This was, after all, a point of divergence in the Supreme Court's reasons in Carter and the government's legislative response: the legal requirement that an individual's death be reasonably foreseeable to be eligible for MAID was engineered by the government, not the Supreme Court. But that leaves open the question whether there are good independent reasons for reserving access only for people who are nearing death. The question is, what is the restriction good for?

One rationale for the restriction might be that if an illness marks no definite or approximate ("reasonably foreseeable") end of life, there is always the chance that it could be treated or cured successfully in the future. A terminal illness, for example, has the characteristic of shortening what would otherwise be considered an individual's expected life span (such that it imposes premature death), whereas something like depression does not, at least not most of the time. ${ }^{35}$ One might interpret this difference as weighing in favour of taking a "wait and see" attitude with respect to the factor of irremediability: what might not be treatable now could become so in the future, and there is no need to rush toward death as long as there is hope. A more general version of this rationale is simply that an individual's assessment of their circumstances could change at some future time, and they may decide they no longer wish to die (whether or not this change results from advances in treatment). For example, Trudo Lemmens writes:

Restricting the procedure to end-of-life situations arguably reduces the negative impact of the premature death of someone who has otherwise still a long period of life ahead. It creates an opportunity for those afflicted by a debilitating illness to overcome what may be only temporarily perceived as being unbearable suffering associated with it. It creates the space for and offers them the option to change their mind and find renewed purpose in life. ${ }^{36}$

Angus Reid, supra note 4. Interestingly, older Canadians are particularly opposed. The report states, "[a]lmost nine-in-ten respondents aged 55 or older $(86 \%)$ say psychological suffering should not, on its own, be grounds for assisted death" (ibid).

34 It might also have to do with the fact that psychological suffering is associated with mental illness, which in turn is associated with diminished capacity. In other words, respondents might have assumed that people suffering psychologically are not competent to make the decision to opt for MAID. This relates to Objections 3 and 4, below.

35 See the discussion of remediability in connection with Objection 2, below.

36 Trudo Lemmens, "Charter Scrutiny of Canada's Medical Assistance in Dying Law and the Shifting Landscape of Belgian and Dutch Euthanasia Practice" (2018) 85 SCLR (2d) 459 at 463. Lemmens also cites this passage courtesy of Dianne Pothier, "The Parameters of a Charter Compliant Response to Carter v Canada (Attorney General), 2015 SCC 5," at 8, online: Social Sciences Research Network $<$ papers.ssrn.com/sol3/papers.cfm?abstract_id=2753167>:

If the person is not at the end of life, physician-assisted death will foreclose over a long period the possibility of the person changing their mind. The odds of a transitory suicidal wish being determinative increase. The opportunities escalate for assessments being distorted by notions of a disabled life not being worth living. Thus vulnerability concerns are substantially magnified if physician-assisted death is not limited to end-of-life conditions, and thus would weigh more heavily in the balance. 
Another rationale involves the value of life itself. Many people consider human life to have an intrinsic value or sometimes "dignity" whatever its circumstances, ${ }^{37}$ and this value weighs against ending one's life early. But for someone who is dying, there is a decrease in terms of the expected value of continuing to live: because they have less life to look forward to, they have less to lose by opting for an early death. Wanting one's life to end, all things being equal, is more reasonable for those who are dying than for those who are not.

Both of these rationales rely on questionable assumptions about the worth of continuing to live indefinitely with the prospect of a future wracked by intolerable suffering. I take it that a premise underlying the recognition of a right to assisted death is that sometimes a person will reasonably regard their life as no longer worth living — that is, they can have good reasons, given their values and circumstances, to conclude that they are worse off alive than dead. More formally, their lives have disutility to them, all things considered. The circumstances of an individual's life can become so inimical to them that they decide they no longer wish to persist in it, and we accept their decision to opt for assisted dying because they are best situated to assess whether there is more expected disutility in their continuing to live than there is in dying. ${ }^{38}$ Both rationales try to undermine the reasonableness of that assessment for patients who are not dying by ascribing some expected value to the future they would lose by opting for an early death: the first by stressing the possibility that a remedy might be found or that they could otherwise end up with a good future after all, and the second by suggesting that there is something valuable about their continued life that the person has just failed to account for.

Responding to the first, it strikes me that if there is no good reason to think a remedy will be forthcoming, or that the person's own assessment will change, then there is also no good reason for a suffering individual to persist in a life that has negative value to them. While it is true that no one can be completely certain about what the future holds, and that an individual should, and almost certainly will, take that into account when deciding about ending their own life, that accounting is theirs to make; they ought not be compelled to endure if they reasonably decide it is not in their interest to do so. And to the suggestion that a long life of intolerable suffering has decisive positive value in any event, I would say (1) it takes a lot of philosophical legwork to conjure a plausible argument for that thesis in the first place, ${ }^{39}$ and (2) absent the success of such an argument, it is not for anyone else to insist that an individual's life is worth living if the individual reasonably concludes it is not.

I disagree; I think life is better characterized entirely as an instrumental good (for the person whose life it is), or maybe a virtual "primary good" - something you want, whatever you want.

This is clearly a matter of respect for autonomy, but it is also a matter of beneficence. If one's being alive really does become a source of disutility to the extent that its badness outweighs the badness of death, then there is an intelligible sense in which dying is in one's best interest. In other terms, dying can sometimes represent a means of advancing one's well-being. In such cases, MAID represents a beneficent act.

Though, of course, many have tried. See e.g. John Keown, "Restoring the Sanctity of Life and Replacing the Caricature: A Reply to David Price" (2006) 26:1 LS 109; John Keown, Euthanasia, Ethics and Public Policy: An Argument Against Legislation (Cambridge: Cambridge University Press, 2002); Neil M Gorsuch, The Future of Assisted Suicide and Euthanasia (Princeton: Princeton University Press, 2006); John Finnis, "A Philosophical Case Against Euthanasia" in John Keown, ed, Euthanasia Examined: Ethical, Clinical and Legal Perspectives (Cambridge: Cambridge University Press, 1995) 23. For a discussion of so-called "sanctity of life" versus "quality of life" views regarding the value of life, see Stephen Smith, "How We Value Life: George Bailey and the Life Not Worthy of Being Lived" in Jon Yorke, ed, The Right to Life and the Value of Life (Farnham, Surrey: Ashgate, 2010) 101. 
The resulting suggestion is this: when it comes to irremediable, intolerable suffering, it is not necessary that it be accompanied by a reasonably foreseeable death in order for it to successfully rob a person of the prospect of a future of value - a future they will be able to participate in at a high-level and take satisfaction from. A person so suffering may have good reasons to want to end their life, regardless of whether they are dying. And if psychological suffering is not different or less urgent than physical suffering, then individuals inflicted with it should have as much right to opt for assisted dying as those suffering physically. But this brings us to the next objection.

\section{B. OBJECTION 2}

Psychological suffering is not of the right kind to justify an assisted death. There is some important difference between psychological suffering and physical suffering that renders MAID unsuitable for individuals suffering the former, but not necessarily the latter.

It is safe to say that few thinking people would deny that mental illness is real or that it can inflict suffering on its victims, but it may still be that such suffering is not of the right kind to justify access to assisted dying. The objection under consideration depends on differentiating psychological suffering from other forms of suffering that justify access to MAID, for example, the physical suffering induced by cancer or ALS. Canadians certainly seem to perceive a distinction: as noted above, almost three-quarters of poll respondents said assisted death should be allowed for non-terminal patients who are in a great deal of physical pain, whereas nearly 80 percent believed those suffering only psychologically should not have access. ${ }^{40}$

Jeanette Hewitt notes that physical suffering tends to be privileged in discussions of rational suicide, and psychological suffering is disregarded "either because it is seen as being insubstantial and ephemeral or because it is attributed to an underlying mental illness which is remediable." ${ }^{\prime 1}$ States like depression and anxiety "have alternatively been seen [as] products of an affluent but disaffected society, personality disorder, weakness of will or a remediable biochemical brain abnormality." 42 In contrast to the pain caused by cancer, the symptoms of mental illness are often perceived as tolerable, transient, and sometimes the product of free will (think of how complaints of depression invite "Pick yourself up!" or "Get over yourself; others have it worse," responses). ${ }^{43}$ Even otherwise, these symptoms are still regarded as more manageable or treatable. This illustrates two ways of distinguishing the relevant forms of suffering that could matter for the issue of assisted dying: (1) psychological suffering is more tolerable or transient than physical suffering; and (2) even where it is severe and intractable, persistent pursuit of treatment is more likely to succeed than for other kinds of chronic pain or disability. As a result, psychological suffering fails to rationalize suicide in the same way physical suffering can, so that we can appropriately reserve MAID for those with physical ailments only.

$40 \quad$ Angus Reid, supra note 4.

41 Jeanette Hewitt, "Why Are People with Mental Illness Excluded From the Rational Suicide Debate?" (2013) 36 Intl JL \& Psychiatry 358 at 360.

$42 \quad$ Ibid at 361 [citation omitted].

43 Indeed, patients with depression often level these imperatives at themselves. 
While discussions of mental illness have become more mainstream, and popular understanding of the matter continues to advance, the notion that suffering due to mental illness is more tolerable, transient, or "less real" than physical suffering unfortunately continues to persist. Queens University Professor Udo Schuklenk was quoted on this score in a National Post article in 2015: "[p] eople make light of the suffering that is involved because they don't appreciate the misery of the quality of life.... Unless they know someone who has had treatment-resistant depression, or they had it themselves, the view is, 'it can't be that bad. Pick yourself up. You're not suffering cancer after all." ${ }^{, 44}$ Even among mental health professionals who would never be so dismissive, there is sometimes a tendency to cast psychological suffering in a strangely philosophical light that physical suffering fails to attract. John Maher writes that his proper role as a psychiatrist is to help his patients "make meaning of their suffering and find hope and purpose no matter what their life circumstances." 45 Thomas Blikshavn, Tonje Husum, and Morten Magelssen similarly stress the importance of hope, arguing that hope itself can be instrumental in relieving a person's suffering, ${ }^{46}$ and that in any event patients who continue to suffer should be directed toward "accepting and embracing the pain as a part of life," and pursuing "growth" rather than "annihilation." ${ }^{.47}$ It is impossible to doubt these clinicians' sincerity, but it is hard to regard assertions about psychological suffering's hidden meaning, its fitting role in a satisfactory life, and exhortations to growth and stoic acceptance as truly contending with the misery of mental illness in its most persistent and severe forms.

Quoted in Sharon Kirkey, "Majority Rejects Assisted Suicide for Mentally Ill, Poll Finds," The National Post (1 April 2016), online: $<$ https://nationalpost.com/news/canada/majority-rejects-assisted-suicide-formentally-ill-poll-finds>.

45 Maher, "What Troubles Me," supra note 7 at 4.

46 This is undoubtedly true in many cases, but Blikshavn, Husum, and Magelssen go further and argue that making MAID available to those with mental illness will necessarily frustrate the efforts of therapists by implicitly countenancing the prospect of hopeless cases: "the very awareness that therapists may in principle come to give up hope in your eventual improvement may be harmful for the patient's perception of herself" (Blikshavn, Husum \& Magelssen, supra note 12 at 156). But this misses something important, namely that making MAID available offers a different form of hope: though MAID is not a means of recovery, it does represent a means of ending one's suffering, and that alone can provide comfort, especially where therapeutic failures persist. Maher, perhaps unwittingly, expresses a similar line of thinking in relation to suicidal thoughts: "for many people suicidal thinking helps keep them alive because it gives them a sense of control: "there is a way out if I ever need it"' (John Maher, "Assisted Death in Canada for Persons with Active Psychiatric Disorders" (2016) 9 J Ethics in Mental Health at 1, online: <https:// www.jemh.ca/issues/v9/documents/JEMH Open-Volume-EditorialAssisted\%20Death\%20in\%20 Canada-May2016.pdf $>$ ). If that is correct, then making MAID available as a way out would benefit individuals distressed by the prospect of indefinite intolerable suffering. Finally, Dembo, supra note 11 at 320 [footnotes omitted], nicely summarizes the issues here this way:

$[\mathrm{P}]$ sychiatrists are trained to prevent suicide at all costs and thus treat patients with increasingly noxious medications and surgeries, when there is often little evidence for their effectiveness in such ill people. These measures can serve to prolong lives of unbearable suffering. The refusal to acknowledge hopelessness can also lead to fractures in the precious therapeutic alliance, which may be the only relationship many of these individuals have at this point in their illnesses.

Psychiatric patients in despair are often deemed irrational by their physicians, purely on the grounds that a suicidal wish is by its nature a symptom of illness, rather than a rational response to an unbearable life or a tragic world. I would instead argue that hopelessness in those with mental illness may, at times, be well founded and should be taken seriously. 
Consider the following examples. Adam Maier-Clayton, a Canadian who suffered refractory mental illness for years and who took his own life as a result, ${ }^{48}$ was interviewed for the Globe and Mail in 2016 and described his suffering this way: "[ $\mathrm{t}$ ]he amount of pain I endure on a day-to-day basis, it would break anyone." ${ }^{49}$ He continued:

In college, I was doing very well, but my OCD and anxiety started to return and I started developing pain that I didn't understand. I thought it would go away, but this psychosomatic pain got worse and worse. You know when you touch your toes, and you feel that burn at the back of your legs? It's like that in my face, in my back, in my head, and it doesn't stop.... Physical illness and mental illness can actually induce the same amount of pain. The only difference is the pain in a physical illness has a physical pathology. In a mental illness, the pain is called psychosomatic pain. To the patient, it feels exactly the same. ${ }^{50}$

\title{
Lewis Wolpert, another sufferer of depression, writes:
}

\begin{abstract}
It was the worst experience of my life. More terrible even than watching my wife die of cancer. I am ashamed to admit that my depression felt worse than her death but it is true. I was in a state that bears no resemblance to anything I had experienced before. It was not just feeling very low, depressed in the commonly used sense of the word. I was seriously ill. I was totally self-involved, negative and thought about suicide most of the time. I could not think properly, let alone work, and wanted to remain curled up in bed all day. I could not ride my bicycle or go out on my own. I had panic attacks if left alone. And there were numerous physical symptoms - my whole skin would seem to be on fire and I developed uncontrollable twitches. Every new physical sign caused extreme anxiety. I was terrified, for example, that I would be unable to urinate. Sleep was impossible without sleeping pills: these only worked for a few hours, and when I woke up I felt worse. The future was hopeless. I was convinced that I would never work again or recover. There was the strong fear that I might go mad. ${ }^{51}$
\end{abstract}

Sidney Kennedy reports that some of his patients have said that their "treatment-resistant depression was worse than having breast cancer," and describe it as "the biggest burden they've ever experienced." 52

A plausible definition of suffering (offered by Hewitt) is that suffering is "any enduring experience of pain or distress that significantly impairs a person's subjective satisfaction with

48 See André Picard, “The Mentally Ill Must Be Part of the Assisted-Dying Debate,” The Globe and Mail (17 April 2017), online: <https://www.theglobeandmail.com/opinion/the-mentally-ill-must-be-part-ofthe-assisted-dying-debate/article34721896/>, reporting on Adam Maier-Clayton's death:

"I am my own saviour. Always have been, always will be." Those are the last words Adam Maier-

Clayton, 27, posted on his Facebook page before taking his own life on Thursday. His death was

not a surprise. Mr. Maier-Clayton had been saying for months that he wanted to end his life, and pleaded publicly for an assisted death. But existing legislation, Bill C-14, requires that death be

"reasonably foreseeable," so he was deemed ineligible. He took matters into his own hands. Adam Maier-Clayton, "As a Person with Mental Illness, Here's Why I Support Medically Assisted Death," The Globe and Mail (8 May 2016), online: <https://www.theglobeandmail.com/life/health-andfitness/health/as-a-person-with-mental-illness-heres-why-i-support-medically-assisted-death/ article29912835/>.

Ibid.

Lewis Wolpert, Malignant Sadness: The Anatomy of Depression (New York: Simon and Schuster, 1999) at vii. The book's introduction is available online: $<$ https:/www.nytimes.com/books/first/w/wolpertsadness.html>.

Sharon Kirkey, "Possibility that Incurable Depression Meets Criteria for Doctor-Assisted Suicide Raises Ethical Concerns," The National Post (13 February 2015), online: <https://nationalpost.com/news/ canada/possibility-that-incurable-depression- meets-criteria-for-doctor-assisted-suicide-raises-ethicalconcerns $>$ [Kirkey, "Ethical Concerns"]. 
his or her quality of life. ${ }^{\prime 53}$ What passages like those above illustrate is that the experience of mental illness is just as capable as physical illness at inflicting such an impairment. If we take such reports seriously, we should admit that suffering due to mental illness can be as bad or maybe even worse than that associated with cancer. It cannot, therefore, be dismissed or downplayed as "suffering-lite" in contrast with physical suffering. If it is true that severe suffering experienced by individuals with physical illness or disability can sometimes rationalize suicide because it robs them of subjective satisfaction in their quality of life, then we must accept the possibility that psychological suffering can do the same. It is worth pointing out that the law in Canada already endorses this proposition. Criminal Code section 241.2(2) includes among the criteria for "a grievous and irremediable medical condition" that the relevant illness cause "enduring physical or psychological suffering. ${ }^{\circ 4}$ In fact, much of the suffering associated with a physical illness can be psychological in nature anyway (feelings of the loss of autonomy, loss of dignity, and so on), so it makes perfect sense to include psychological suffering under these criteria. This presses the conclusion that psychological suffering is just as real and should be as important as "physical" pain in deciding questions about MAID. In terms of the impact they can have on an individual and his or her life, they are on a par, and both can rationalize a desire to see one's life end.

What about the proposition that persistent pursuit of treatment for mental illness is more likely to succeed than for other kinds of chronic illness or suffering? This question is related to the first objection above, namely that only those who are dying should be eligible for MAID. We saw that it is difficult to conclude that only dying patients should have access since mere suffering itself can be just as effective as a shortened life at robbing an individual of a future of value, and that ending one's life could be preferable to living in either case. The issue here is the relative remediability of psychological and physical suffering. In terms of Objection 2, what matters is whether persistent pursuit of treatment is more apt to remedy suffering rooted in mental illness than suffering rooted in physical illness. ${ }^{55}$ If mental illness is more remediable than physical illness or disability, then that may be a reason to reserve MAID for those suffering physically.

This objection is difficult to evaluate because it substantially depends on what makes an illness count as "irremediable." Because mental illnesses like depression do not characteristically impose a reasonably foreseeable death, the period during which different treatments can be attempted is theoretically indefinite. Combine that with the myriad avenues of treatment for depression, and the fact that it can be episodic - acute periods of suffering interspersed with periods of remission during which life is tolerable - it is no wonder that health professionals and others are prone to distinguish psychological and physical illness. For example, in an interview with the National Post, Sidney Kennedy distinguishes depression from illnesses like "late-stage pancreatic cancer, for which no known treatments available today will ultimately stop the "downward spiral to death,"” saying "[o]ur field [of psychiatry] is moving forward, and I would not want to be in the position of saying, "if we hadn't assisted death and dying in this person five years ago, they could have had a particular

Hewitt, supra note 41 at 361 .

Criminal Code, supra note 5, s 241.2(2) [emphasis added].

It is worth saying that this kind of language obscures the fact that "physical" or biological factors underlie many forms of mental illness. See e.g. Dennis S Charney et al, eds, Charney \& Nestler's Neurobiology of Mental Illness, 5th ed (New York: Oxford University Press, 2018). 
treatment that we now see works.",56 Jean Echlin of the Euthanasia Prevention Coalition similarly remarks, "[i]f somebody loses their life now, they're put to death, and two weeks from now there's a breakthrough, they've lost their life when they could have had quality." ${ }^{57}$ Centre for Addiction and Mental Health (CAMH) psychiatrist Alexander Simpson writes that "[n]ew treatments are possible, new types of therapy can assist, and new ways of thinking about being someone living in recovery are always available.... We do not yet know enough about when or if someone will recover or if the severity of their disorder will remit in time. ${ }^{, 58}$ Allison Crawford, another CAMH psychiatrist, puts the matter like this:

\footnotetext{
I think it's also important to say that people with mental illness aren't excluded from the proposed legislation if they do have an illness that's deemed irremediable. So, for example someone with depression and ALS would not be excluded from the legislation, but the conversation about when mental illness becomes irremediable or untreatable, I think is a long conversation that's needed. The recovery orientation that most of us has makes that a difficult conversation, and one that I'm glad we're not rushing into. ${ }^{59}$
}

Given the factors mentioned above, it is advisable not to be too quick to ascribe irremediability even to refractory mental illness. That said, we should not adhere to the conceit that all cases of psychological suffering will be remediable such that ending one's life is always irrational. No matter how many forms of treatment are attempted, the suffering might continue. ${ }^{60}$ In those cases (which are relatively rare $^{61}$ ) it is unreasonable to indefinitely require people to endure extreme suffering while they wait for an effective treatment that may never come. Many individuals suffering from mental illness seem to agree. For example, Graeme Bayliss:

Perhaps, contrary to my own self-imposed and deeply ingrained prospectus, my depression and anxiety and OCD will dissolve blissfully away — or at least become manageable — and I will achieve the average lifespan of a Canadian man. But the government will not, on the basis that a cure might eventually be found, ban ALS patients from assisted suicide. So why should they stop the chronically depressed because they have "good days and bad days"? Even on the good days, I know the bad days are coming. ${ }^{62}$

Kirkey, "Ethical Concerns," supra note 52.

Quoted in Lisa Xing, "My Life is a Nightmare': Windsor Man, 27, Wants Legally Assisted Death" CBC News (31 October 2016), online: <www.cbc.ca/news/canada/windsor/assisted-dying-mentally-ill-1.38 29839>.

Alexander IF Simpson, "Medical Assistance in Dying and Mental Health: A Legal, Ethical, and Clinical Analysis" (2018) 63:2 Can J Psychiatry 80 at 82.

"The Current Transcript for April 25, 2016," CBC Radio (25 April 2016), online: <www.cbc.ca/radio/ thecurrent/the-current-for-april-25-2016-1.3551316/apr-25-2016-full-episode-transcript-1.3552563>. Keep in mind that the range of treatments attempted will be limited by what the patient finds acceptable (Criminal Code, supra note 5, s 241.2(2)(c)).

This is reflected in the fact that even where MAID is available for those suffering solely from mental illness, such cases represent a tiny number of successful applications for assisted dying — about 1 percent in the Netherlands, for example: Senay Boztas, "Netherlands Sees Sharp Increase in People Choosing Euthanasia Due to "Mental Health Problems,"' The Telegraph (11 May 2016), online: $<$ https://www.telegraph.co.uk/news/2016/05/11/netherlands-sees-sharp-increase-in-people-choosingeuthanasia-du/>. The "sharp increase" reported in the title represents an increase from 2 cases in 2010 to 56 in 2015, out of about 5500 total reported cases of euthanasia and assisted suicide (Boztas, ibid). Graeme Bayliss, "It Doesn't Get Better," The Walrus (14 April 2016), online: <https://thewalrus.ca/ suicide-is-not-painless/>. 
And Maier-Clayton:

People say, we don't know how you're going to feel tomorrow. And that's true. None of us has a time machine. But if you have someone who has been suffering for 10 straight years, no matter how much effort and genuine treatment they have endured, and they've been confident about this decision for a long time, it's rather nonsensical to say, "Hey, you don't know what's around the corner. Just stick around." It's not the sufferers' responsibility to wait for modern medicine to develop to an appropriate level. ${ }^{63}$

Similar to what we saw in connection with Objection 1, the suggestion here is that if there is no good reason to think that another treatment for a case of refractory mental illness will be any more successful than others already attempted, then there is also no good reason for a suffering individual to persist in a life that has negative value to them. A continuing lack of success will tend to rationalize ending one's life over time, and the law should take recognition of that fact.

To drive home this point, consider the remarks in an open letter by Belgian mental health professionals opposed to assisted dying for the mentally ill: "[w]e see that some who were first declared incurable, eventually abandon euthanasia because new prospects showed up. In a paradoxical way, this proves that the disease can not be called incurable." ${ }^{64}$ It is no doubt true that some who contemplate assisted death after having committed to long periods of unsuccessful treatment may change their minds if a course of treatment is eventually found that alleviates their suffering. This is the same for any disease: if a terminally ill cancer patient requests an assisted death, but they are miraculously cured before it is carried out, then the reason for their wish to die will dissolve. But that possibility is ultimately irrelevant to the question of whether it was rational for them to seek assisted death if they were offered no good reason to think that a different treatment would be successful. What matters for a rational desire to see one's life end are the reasons an individual has to think their suffering can be remedied (by a treatment acceptable to them). What would count as a good reason? Statistical evidence could qualify. If we show that other relevantly similar patients - those with a similar illness who have undergone a similar prior course of treatment — have had success with a different course of treatment, then that would be a good reason to try that course. The point is that perpetual stabs in the dark are not going to be enough. The mere metaphysical possibility that a remedy could manifest will not rationally undermine a decision to seek assisted dying when a person decides they have suffered long enough. ${ }^{65}$

63 Maier-Clayton, supra note 49 [emphasis added].

64 Quoted in Charles Lane, "Europe's Morality Crisis: Euthanizing the Mentally Ill," The Washington Post (19 October 2016), online: $<$ https://www.washingtonpost.com/opinions/europes-mortality-crisis-euthan izing-the-mentally-ill/2016/10/19/c75faaca-961c-11e6-bc79-af1cd3d2984b story.html $>$.

65 Blikshavn, Husum, and Magelssen object that this kind of statistical logic fails in the context of mental illness because it is often difficult to "identify and characterize the pathophysiological mechanism" underlying it, and that relying on statistics to make a prediction of prognosis "amounts to an unjustified generalization to the individual from an actuarial risk assessment" (Blikshavn, Husum \& Magelssen, supra note 12 at 153). But surely statistics and "actuarial" assessments can still be useful instruments for decision-making, regardless of whether we have complete knowledge of the mechanisms on which they supervene. After all, mental health treatments are chosen and applied even when the nature of the pathophysiology underlying an illness is uncertain. But if diagnostic omniscience is not required to decide on courses of treatment, it should also not be required to decide that enough is enough. 
It is sometimes said that making assisted dying an option for such patients amounts to abandoning them. For example, in a companion interview in the Globe and Mail contrasting with Maier-Clayton's, depression sufferer Mark Henick says,

I think we could be making much more progress in finding true cures and also helping people improve their quality of life if we were to actually pay better attention to helping them recover and building support systems that they need. If we were to offer assisted dying to people who have mental-health disorders, I feel like we'd be giving up on them. It's as if policy-makers would be saying, "Look, we're not willing to help you get better, but at least we're willing to help you die." That doesn't make any sense to me. ${ }^{66}$

As a sort of converse point, continuing to pursue treatment after treatment in the context of apparent futility might amount to a different sort of abandonment: that of leaving a patient to suffer indefinitely because of a conceit that if we just try hard enough we can solve the problem. It essentially imposes a duty on the sufferer to continue to stoically endure while we grasp at straws. That makes little sense as well. But in his article, Henick makes an important point that this response obscures: that in a substantial number of cases, a contributor to the suffering of mental illness is the failure of the healthcare system to appropriately respond to mental illness in the first place. For at least some chronic sufferers, the problem is not that treatment is ineffective, but that potentially effective treatment is either never tried or is unavailable. ${ }^{67}$ As one Vancouver palliative care doctor says, "[t]here are often long waits for psychiatric referral and care ... I would hate for someone to not get proper treatment and feel like there is really no other way to relieve themselves of the suffering but to consider physician-assisted death." ${ }^{68}$

There may be no satisfying reply here, except to say that the previous point stands: if there are no good reasons to think the mental health system will get its act together in a sufficiently timely way to intervene appropriately in particular cases of chronic, intolerable psychological suffering, then simply expecting those individuals to continue suffering indefinitely seems like an evasion. If anything, it compounds our abandonment of them. Parallel to Henick's remarks, it is as if policy-makers would be saying: "look, we may not be prepared to help you get better, and yes you may suffer endlessly, but at least we're not willing to help you die." ${ }^{\circ 9}$ The alternative is an unpalatable response to an intolerable situation, but it may have an upside (I am speculating here): allowing assisted dying in these cases offers the sufferers a way out where they otherwise have none, and furthermore, seeing people forced into assisted dying in such cases could bring into relief the inadequacies of mental health

Mark Henick, "Why People with Mental Illness Shouldn't Have Access to Medically Assisted Death," The Globe and Mail (8 May 2016), online: <https://www.theglobeandmail.com/life/health-and-fitness/ health/why-people-with-mental-illness-shouldnt-have-access-to-medically-assisted-death/ article29912867/>.

${ }^{67}$ Harvey Chochinov reports that " $[\mathrm{m}]$ ental illness is one of the best predictors, more so than poverty, of inequitable access to healthcare in Canada" (Harvey Max Chochinov, "The Risky Concept of Mental Illness Assisted Suicide," The Huffington Post (28 March 2016), online: <https://www.huffington post.ca/harvey-max-chochinov/assisted-suicide-mental-illness_b_9541656.html $>$ ).

68 Romayne Gallagher, quoted in Wendy Glauser, Michael Nolan \& Jeremy Petch, "Should People with Mental Health Disorders Have Access to Physician-Assisted Death?," online: < healthydebate.ca/2016/ 01/topic/should-people-with-mental-health-disorders-access-assisted-death/>.

69 This remark from Maier-Clayton seems to apply: "[i]f someone is suffering for years and years like myself, then what are you protecting them from? ... You're not protecting them. You're confining them to pain" (quoted in Xing, supra note 57). See also the comment about beneficence in supra note 38. 
treatment and motivate positive change. ${ }^{70}$ Everyone would hate for someone to not get proper treatment and feel like there is really no other way to relieve themselves of the suffering but to consider physician-assisted death. We all would rather see people live than die, but we must also acknowledge the circumstances of the lives we are expecting them to live. If their suffering is so great that it threatens to rob them of a future of value, then there is a moral imperative to either offer them the realistic possibility of such a future, or to let them go. Consigning them to the prospect of unending intolerable suffering ends up as the worst option, and we must take responsibility for the failure to help them and fix the problem rather than ignore them and expect them to endure. Put another way, the need for better public policy in respect of the quality and availability of mental health treatment should not obscure the fact that there are individuals, living under the current system, whose interests are further violated by denying them access to assisted dying. Compelling someone to live against their rational will after we have failed to help them is not a solution or a prophylactic to the consequences of that failure, much as our consciences may like it to be.

To summarize, the objection that psychological suffering is not of the right kind to justify access to assisted dying seems to fail. A suffering person may have decisive reasons to want to see their life end, regardless of whether they are suffering physically or psychologically.

\section{ObJection 3}

Mental illness necessarily vitiates or contaminates competence and clear thinking. It is not possible for sufferers of mental illness to make a fully autonomous decision to end their own life, so it is inappropriate to extend access to MAID to individuals with mental illness.

This is one of the most commonly deployed objections to allowing assisted dying for mental illness, and examples of it are easy to find. Opinion writer Charles Lane worries, in The Washington Post, that "by definition, the mentally ill may be less capable of forming a "true will.," 71 Andrew Lawton (referring to individuals with suicidal depression) baldly asserts that "[s]uicidal people are irrational. This is true even when decisions appear to be made through logic and reason." ${ }^{, 72}$ Blikshavn, Husum, and Magelssen suggest that suicidal behaviour, and "by extension assisted suicide," should be conceptualized as "dysfunctional

Kathryn L Tucker, "Building Bridges Between the Civil Rights Movements of People with Disabilities and Those with Terminal Illness" (2017) 78:3 U Pitt L Rev 329 notes the improvements in end-of-life care since assisted dying became available in Oregon at 345-46 [footnotes omitted]:

[R] ather than posing a risk to patients or the medical profession, the open availability of aid in dying has galvanized significant improvements in the care of those terminally ill and dying in Oregon. Oregon physicians report that since aid in dying has been openly available, they have worked hard to improve end-of-life care, taking educational courses on how to treat pain in the terminally ill and how to recognize depression and other psychiatric disorders, and more frequently referring patients to hospice. Surveyed on their efforts to improve end-of-life care since aid in dying became available, $30 \%$ of responding physicians had increased referrals to hospice care and $76 \%$ made efforts to improve their knowledge of pain management. Hospice nurses and social workers surveyed in Oregon observed an increase in physician knowledge of palliative care and willingness to refer to hospice.

Lane, supra note 64.

Andrew Lawton, "Commentary: Assisted Suicide is an Affront to Mental Illness, Not a Cure for It," Global News (21 April 2017), online: < https://www.globalnews.ca/news/3389850/commentary-assistedsuicide-is-an-affront-to-mental-illness-not-a-cure-for-it/>. 
problem-solving" in the context of mental healthcare. ${ }^{73}$ Conservative MP Gérard Deltell once rhetorically remarked: "[a]t what point does someone suffering from a mental illness offer his or her full and complete consent? It's impossible." 74

For some reason this objection is less commonly raised for cases where a patient is mentally ill but also has an illness like cancer as a comorbidity. Usually Objection 3 is advanced in connection with cases where an individual contemplates suicide solely because of psychological suffering. ${ }^{75}$ The explanation for this is uncertain: perhaps it is a product of a greater concern for Objections 1 and 2 - that MAID should be reserved for those who are dying, or that only physical suffering can justify a decision to seek it. But perhaps these dualillness cases are simply overlooked; if Objection 3 holds, then we should reconsider access for dual-illness patients as well. If patients with mental illness truly are incapable of "offering their full and complete consent," then maybe mentally ill patients suffering from a life threatening comorbidity should be denied access as well as those who are not.

This objection does not go as far as the "no rational suicides" thesis, but asserts something related: that among mentally ill patients, a decision to end one's life is necessarily contaminated by some capacity-limiting feature of their illness. Hewitt explains the issue this way:

Suicidal ideation associated with acute psychological crisis is rightly not considered relevant to any discussion of rational suicide. Should however the same judgements be made about chronic psychological pain in the context of enduring mental illness? Chronic mental illness is qualitatively and quantitatively different to temporary psychological distress. The person may suffer repeated acute episodes of illness and also enduring changes in psycho-social functioning that have far reaching consequences for the person's quality of life.... [The] absolute approach to the prevention of suicides for those with mental illness is founded on assumptions about the general inability of most people with serious mental illness to be rational. ${ }^{76}$

The "assumptions" about the incapacity or rationality of mentally ill individuals are implicit in remarks like Lane's, Lawton's, and Deltell's. But a decision to opt for assisted dying is not necessarily irrational, even for someone with a mental illness like depression. For such a person, the wish to die will not always be a symptom of their illness. We saw earlier that a desire to die will not always be pathological, and it similarly will not always be pathological among those with mental illness. There is no definitional or conceptual component of mental illness, even suicidal depression, that renders a sufferer unable to make a competent decision to seek an assisted death.

Hewitt distinguishes between

a) those whose suicidal desires arise directly from a treatable mental illness, and whose life circumstances, were the illness to be successfully treated, would make life worth living and b) those who experience

Blikshavn, Husum \& Magelssen, supra note 12 at 155.

Quoted in Daniel LeBlanc, "Canadians Want Restrictions on Doctor-Assisted Dying, Poll Suggests,"

The Globe and Mail (7 April 2016), online: <https://www.theglobeandmail.com/news/politics/ canadians-want-restrictions-on-doctor-assisted-dying-poll-suggests/article29548237/>.

See Stefan, supra note 8 at 31-32.

Hewitt, supra note 41 at 362-63. 
enduring suffering because of mental illness, which cannot be successfully treated in a way acceptable to the person. $^{77}$

Putting the matter in terms of (reasonably) acquired hopelessness, Hewitt writes:

\begin{abstract}
Hopelessness experienced as a result of a realistic perspective on the course, costs and consequences of living with serious mental illness would seem a reasonable response in some circumstances where treatments have proved ineffective and remission or recovery has not occurred. Yet, despite the real losses often experienced by the mentally ill, this choice has generally been viewed as inauthentic. ${ }^{78}$
\end{abstract}

One problem with viewing these choices as necessarily inauthentic is that most patients with chronic, refractory mental illness are still competent on standard forms of assessment. Stefan spends a great deal of time establishing and explaining this in Rational Suicide, Irrational Laws (see her story about Josh Sebastian at the beginning, for starters), and there is no need to reprise it all here. ${ }^{79}$ The point is that mental illness does not necessarily rob people of the ability to make genuine, authentic assessments of their own circumstances and the value of continuing to be alive. Those assessments should be taken seriously. ${ }^{80}$

There is a difference between a suicidal desire that is a feature or symptom of depression, and a desire for death rooted in a person's assessment of their circumstances in suffering from depression. The experience of depression is wretched, and a prolonged intolerable engagement with it could rationalize a second-order decision to seek assisted dying - a decision based on considering the benefits and costs of continuing to be alive. This is how Maier-Clayton regarded his case: "[n]on-existence is better than this.... The real reason for someone like me wanting the right to die is simple: Once there's no quality of life, life is akin to a meaningless existence." 81 A depressed character in Infinite Jest expresses the secondorder nature of her wish to die even more succinctly: "[d]o you understand? It's not wanting to hurt myself it's wanting to not hurt." ${ }^{, 82}$ Particularly for individuals that have committed to treatment but have found no success, the circumstances of their illness can underlie a reasonable decision to seek an assisted death. Their decision-making is not necessarily contaminated by their illness, even if their illness is largely responsible for the circumstances motivating the decision. It is the same as with any "grievous and irremediable" illness.

\title{
$77 \quad$ Ibid at 363.
}

78 Ibid [emphasis added].

79 Stefan, supra note 8 at 1-7. See also Justine Dembo, Udo Schuklenk \& Jonathan Reggler, “"For Their Own Good': A Response to Popular Arguments Against Permitting Medical Assistance in Dying (MAID) Where Mental Illness Is the Sole Underlying Condition" (2018) 63:7 Can J Psychiatry 451 at 453. For some concerns pertaining to the inadequacy of standard forms of assessment in the context of MAID, see Louis C Charland, Trudo Lemmens \& Kyoko Wada, "Decision-Making Capacity to Consent to Medical Assistance in Dying for Persons with Mental Disorders" (2016) 9 J Ethics in Mental Health, online: <https://www.jemh.ca/issues/v9/documents/JEMH Open-Volume Benchmark Decision Making to Consent to Medical Assistance in Dying-Maȳ2016-rev.pdf>.

80 Maier-Clayton, supra note 49, dismisses Objection 3 this way:

You're going to hear a lot of people say that legally, it makes no sense to give the mentally ill access to the right to die because they can't possibly give informed consent. But to insinuate anyone who struggles with depression or anxiety or any type of mental disorder is so out of it they can't give informed consent is absolutely inherently wrong.

$81 \quad$ Quoted in Xing, supra note 57.

82 David Foster Wallace, Infinite Jest (New York: Little, Brown and Company, 1996) at 78 [emphasis in original]. 
Objection 3 does not represent a cogent reason to deny mentally ill individuals access to assisted dying.

\section{OBJECTION 4}

It is impossible for us to know if a mentally ill person's decision to seek assisted dying is competent or authentic. Mental illness imposes special conditions (intrinsic and practical) that do not necessarily vitiate competence or clear thinking, but which do vitiate our ability to soundly determine them. It is therefore inappropriate to extend access to MAID to the mentally ill.

In contrast to Objection 3, this objection does not claim that no one with mental illness can make a competent decision to end their own life, but merely that mental illness makes it impossible or too difficult to soundly determine if their decision is competent. How do we "tease apart whether a request for aid in dying arises from a person's mental state related to their illness ... or sound reasoning based on a desire to escape prolonged suffering"? ${ }^{83}$ Lane asserts that the intentions of the mentally ill are "intrinsically more difficult for a doctor or anyone - to establish with the necessary certainty upon which to base a life-or-death decision," and eventually concludes that access being allowed in certain European jurisdictions "represents a global moral crisis for psychiatry, and all of medicine." ${ }^{84}$ Harvey Chochinov observes the hopelessness and sense of worthlessness that mental illness can inflict, and sees that "a death hastening response is fraught with hazard." 85

The objection that there are intrinsic and practical obstacles to soundly assessing the authenticity of any patient's wish to die, and a fortiori, those of the mentally ill, was explicitly raised by Canada and several interveners in Carter. In its intervener factum, the Canadian Medical Association submitted that the trial judge had understated "the challenges physicians will face in making these assessments ... especially in the end of life care context where the consequences of decisions are particularly grave and in a public medical system in which resource constraints are a pressing issue. ${ }^{" 86}$ Continuing:

Such important decisions are best made following careful discussions between physician and patient, well in advance, concerning the patient's end of life wishes generally. The CMA and its provincial and territorial medical association colleagues note that these types of discussions do not now routinely occur, and that when they do, patients' assessments of their goals can and do evolve over the course of their illness.... It may be very difficult to assess competency and voluntariness in some patients (for example, the very old, the very ill and the depressed) and in some settings ... where there may not be an established physician-patient relationship. $^{87}$

The Canadian Press, "Deciding on Assisted Death in Context of Mental Illness Highly Complex, Experts Say," CBC News (6 March 2016), online: $<$ https://www.cbc.ca/news/health/assisted-dying-mentally-ill$1.3478218>$.

$84 \quad$ Lane, supra note 64

85 Chochinov, supra note 67. Chochinov writes that "[t]he nature of mental illness often leads people to see themselves as worthless, to believe that their situation is hopeless; and to perceive - often reflected through society's judgmental gaze - that their lives have little value" (ibid).

86 Carter, supra note 1 (Factum of the Intervener, the Canadian Medical Association at para 24), online: $<$ https://www.scc-csc.ca/WebDocuments-DocumentsWeb/35591/FM230_Intervener_CanadianMedical-Association.pdf $>$ [footnotes omitted].

87 Ibid at para 25 [footnotes omitted]. 
The Euthanasia Prevention Coalition and the Euthanasia Prevention Coalition - British Columbia submitted that

[d]epression and subjective loss of dignity experienced by people certainly impacts such decisions and it is impossible for depressed patients to be completely separated from others seeking assisted suicide. Assessing capacity and voluntariness accurately is difficult, and often impossible. ${ }^{88}$

\title{
Canada's factum contained these passages:
}

\begin{abstract}
The evidence from both parties' experts showed that determining, for example, the role of depression in decision-making is difficult, even by expert assessment. Doctors in Oregon involved in assisted suicide do not appear to comply with the requirement for referral to a mental health professional for patients suffering from depression which may impair judgment. The appellants' witnesses documented cases in Oregon of patients with major depressive disorders being provided with lethal prescriptions, and concluded that the Oregon system may fail to protect some patients with mental illnesses.
\end{abstract}

The trial judge acknowledged that capacity assessments in the context of requests for assisted death require an in depth knowledge of the patient. In most of the European jurisdictions, most doctors have long term relationships with their patients. As one of the appellants' experts testified, that is generally not the case in Canada, but she was of the view that physicians would take the necessary time to conduct multiple interviews and collect collateral information. The evidence from Oregon showed that $50 \%$ of patients who receive a lethal prescription have known the prescribing doctor for less than ten weeks and some are given such prescriptions by doctors who have known them for less than one week. ${ }^{89}$

This objection is superior to Objection 3 because it leaves room for the true proposition that mentally ill people can in principle make competent, authentic decisions respecting a wish to die. The "hazard," however, lies in a perceived inability to determine the authenticity of vulnerable patients' wishes, like those of patients with mental illness. Despite our best efforts, we may fail to protect some patients with mental illnesses from pursuing an inauthentic, ingenuine decision to die.

The Supreme Court explicitly rejected this argument on the grounds that it is possible to soundly assess a patient's vulnerability on a case-by-case basis (employing "individual assessments"), and that safeguards can be erected to ensure protection of the mentally ill and other vulnerable patients. It also noted that the problems associated with assessing decisionmaking among the vulnerable already arise in the medical system - for example, in end-oflife decision-making and requests to withdraw treatment — and that we already assume in such cases that decision-making can be soundly assessed; there are no logical grounds for

88 Carter, ibid (Factum of the Interveners, Euthanasia Prevention Coalition and Euthanasia Prevention Coalition - British Columbia at para 39), online: $<$ https://www.scc-csc.ca/WebDocuments-Documents Web/35591/FM210_Intervener_Euthanasia-Prevention-Coalition-and-Euthanasia-Prevention-Coalition-

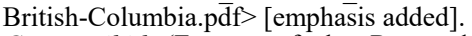

89 Carter, ibid (Factum of the Respondent at paras 35, 37), online: <https://www.scc-csc.ca/ WebDocuments-DocumentsWeb/35591/FM030_Respondent_Attorney-General-of-Canada.pdf $>$ [footnotes omitted] [Respondent's Factum]. 
distinguishing assisted dying from these other cases. It is worth quoting the Supreme Court's reasons at length:

At trial Canada went into some detail about the risks associated with the legalization of physician-assisted dying. In its view, there are many possible sources of error and many factors that can render a patient "decisionally vulnerable" and thereby give rise to the risk that persons without a rational and considered desire for death will in fact end up dead. It points to cognitive impairment, depression or other mental illness, coercion, undue influence, psychological or emotional manipulation, systemic prejudice (against the elderly or people with disabilities), and the possibility of ambivalence or misdiagnosis as factors that may escape detection or give rise to errors in capacity assessment. Essentially, Canada argues that, given the breadth of this list, there is no reliable way to identify those who are vulnerable and those who are not. As a result, it says, a blanket prohibition is necessary.

The evidence accepted by the trial judge does not support Canada's argument. Based on the evidence regarding assessment processes in comparable end-of-life medical decision-making in Canada, the trial judge concluded that vulnerability can be assessed on an individual basis, using the procedures that physicians apply in their assessment of informed consent and decisional capacity in the context of medical decision-making more generally. Concerns about decisional capacity and vulnerability arise in all end-of-life medical decision-making. Logically speaking, there is no reason to think that the injured, ill, and disabled who have the option to refuse or to request withdrawal of lifesaving or life-sustaining treatment, or who seek palliative sedation, are less vulnerable or less susceptible to biased decision-making than those who might seek more active assistance in dying. The risks that Canada describes are already part and parcel of our medical system.

As the trial judge noted, the individual assessment of vulnerability (whatever its source) is implicitly condoned for life-and-death decision-making in Canada. In some cases, these decisions are governed by advance directives, or made by a substitute decision-maker. Canada does not argue that the risk in those circumstances requires an absolute prohibition (indeed, there is currently no federal regulation of such practices). In A.C., Abella J. adverted to the potential vulnerability of adolescents who are faced with life-anddeath decisions about medical treatment.... ${ }^{90}$ Yet, this Court implicitly accepted the viability of an individual assessment of decisional capacity in the context of that case. We accept the trial judge's conclusion that it is possible for physicians, with due care and attention to the seriousness of the decision involved, to adequately assess decisional capacity.

The trial judge, on the basis of her consideration of various regimes and how they operate, found that it is possible to establish a regime that addresses the risks associated with physician-assisted death. We agree with the trial judge that the risks associated with physician-assisted death can be limited through a carefully designed and monitored system of safeguards. ${ }^{91}$

The notion of individual assessments is central in these passages. Both the medical system and the law already implicitly assume that individual assessments can render sound conclusions about a patient's decision-making. We can, and do, tease out impulsive or compromised decisions from those that are authentic. We already do this in respect of the on the basis of her religious beliefs: AC v Manitoba (Director of Child and Family Services), 2009 SCC 30 .

Carter, supra note 1 at paras 114-17 [emphasis added] [citations omitted]. 
decision-making capacity of mentally ill patients in every other context where they decide about or consent to medical treatment, including end-of-life care decisions. A conclusion that it is impossible or too difficult for us to determine the authenticity of decisions of the mentally ill would seem to indict a great deal of standard medical practice and the law that frames it. Without solid empirical evidence to support such a conclusion, it seems clear that it is untenable. Until such evidence is offered, we must assume that it is indeed possible to soundly assess the decision-making of the mentally ill.

There is an argument that, because of the special circumstances of the mentally ill, and the finality of a decision to die, the standards on which their decisional capacity is assessed in these cases ought to be stricter than usual. But this is likewise difficult to defend. On the possibility of heightened standards of competence, Stefan writes:

[O]ur legal framework, of course, assumes (as it must, to be of any utility at all) that competence is objective and determinable.... There are some scholars who argue that a decision to die is final and unusual enough that heightened standards for competence should be applied, including whether the decision is "well considered and consistent with their stable and enduring desires." I agree that there should be heightened standards around a decision to die, but deeply and profoundly disagree that these should be accomplished by requiring a higher bar for competence.... To me, the rule of thumb is: Would this person's consent to treatment be accepted without hesitation? If so, the person is competent. There are other ways to create barriers to suicide.... Competence is too slippery and value-laden a concept, and the finding of incompetence too great an annihilation of an individual's agency, to locate the necessary discretion for individual decision making in competence doctrine. ${ }^{92}$

Perhaps the real objection here is to how the law and standard medical practice approach these cases - that perhaps we are too quick to accept consent to treatment by the mentally ill, and fail to consider the risk that their illness contaminates decision-making. This rings untrue, however, and again would need considerable empirical justification. It is unlikely such evidence could ever be advanced. It certainly has not been advanced so far. On that basis, then, Objection 4 does not represent a cogent reason to deny mentally ill individuals access to assisted dying.

\section{E. OBJECTION 5}

\section{Even assuming that some cases of psychological suffering from mental illness would rationalize MAID, and we could know with a great deal of certainty in individual cases that the person's wish is genuine and expresses their authentic interests, the door should remain closed lest we put others at risk. No regime of safeguards could be 100 percent effective at protecting the vulnerable, including mentally ill patients.}

This objection is perhaps the most cogent, since it does not rely on false premises. It does not deny that some suicides are rational, and is compatible with the proposition that we can soundly evaluate the decision-making of mentally ill patients. Mental illness necessarily vitiates neither competence, nor our ability to be certain in individual cases that a patient's desire to resort to MAID is authentic. Some mentally ill patients will rationally desire to die, 
we will be able to know their decision is competent, and in an ideal world we would be able to grant their wish. Still, this objection goes, in allowing them access to assisted dying, we can expect mistakes to occur. No matter what safeguards are imposed, no matter how meticulous our evaluations, no matter how certain we are, abuse and error will never be completely extricated from the assisted dying equation. The vulnerable will still be vulnerable, and despite our sincerest best efforts, some individuals will inevitably fall through the cracks. The only way to prevent this is to maintain a blanket prohibition on assisted dying, if not for everyone, then at least for the most vulnerable, including the mentally ill. To do otherwise means adopting a posture of "acceptable losses" in relation to vulnerable patients, and doing so is morally fraught. ${ }^{93}$ It invites the medical professions to violate, however rarely, the principle of non-maleficence, and says to the vulnerable that we are willing to subject them to a risk of a premature death to accede or advance the (however genuine) suicidal desires of certain others. We should, therefore, prohibit access to assisted dying for vulnerable patients, including the mentally ill.

The nature of this objection is that the interests of vulnerable individuals cannot be fully reconciled with the interests of capable individuals with a genuine desire for MAID. This is not far-fetched; as with most things in medicine, it is likely that despite whatever restrictions and protections we adopt, errors will occur and some among the vulnerable will indeed slip through the cracks and be enabled to die prematurely. That this is possible can and has been employed in legal arguments against allowing MAID at all; for example, Justice Sopinka in Rodriguez v. British Columbia (Attorney General) suggested that there was "no halfway measure that could be relied upon with assurance" to protect the vulnerable and that there is no assurance an exception to the prohibition could be strictly limited to "those who are terminally ill and genuinely desire death." 94 In Carter, the government argued exactly this in order to establish that a total ban on assisted death is necessary:

\footnotetext{
The effectiveness of the trial judge's proposed alternative means [of preventing the inducement to suicide of vulnerable persons] is purely speculative, and accepts too much risk. This is underscored by the trial judge's bold pronouncement that "it is extremely unlikely that physicians in Canada would be other than rigorously compliant with legislation." Her faith in the medical community is admirable, but to be more circumspect in any prediction is not to condemn the ethics or diligence of doctors: it is a simple recognition that diagnoses of imminent death may sometimes be false, that diagnosis of a remediable mental condition may have been missed, that unconscious biases are exceedingly difficult to overcome, or that opportunities for palliation may not have been tried. Physicians may aspire to rigorous compliance, but they are human. The evidence from Belgium, the Netherlands, and Oregon showed just that. ${ }^{95}$
}

The Supreme Court of course disagreed that this argument meant a blanket prohibition should be maintained, suggesting that it was the government that was speculating about risk

This is the thrust of Scott Kim and Trudo Lemmens' caution against expanding eligibility to individuals with mental illness: "[p]erhaps those who advocate for extending access to people with psychiatric disorders may be willing to tolerate a number of potentially avoidable premature deaths as acceptable because access to assisted dying is felt to be so important in principle. However, that argument must be made explicit and debated publicly" (Scott YH Kim \& Trudo Lemmens, "Should Assisted Dying for Psychiatric Disorders Be Legalized in Canada?” (2016) 188:14 CMAJ E337 at E338). evidence from Belgium and the Netherlands continues to be marshalled in arguments against expanding access to MAID: see especially Lemmens, supra note 36. 
to the vulnerable and that Canada had failed to meet its burden of showing that a blanket prohibition was minimally impairing:

Canada ... argues that the permissive regulatory regime accepted by the trial judge "accepts too much risk", and that its effectiveness is "speculative"... In effect, Canada argues that a blanket prohibition should be upheld unless the appellants can demonstrate that an alternative approach eliminates all risk. This effectively reverses the onus under s. 1, requiring the claimant whose rights are infringed to prove less invasive ways of achieving the prohibition's object. The burden of establishing minimal impairment is on the government.

The trial judge found that Canada had not discharged this burden. The evidence, she concluded, did not support the contention that a blanket prohibition was necessary in order to substantially meet the government's objectives. We agree. A theoretical or speculative fear cannot justify an absolute prohibition. As Deschamps J. stated in Chaoulli, at para. 68, the claimant " $\mathrm{d}[\mathrm{oes}]$ not have the burden of disproving every fear or every threat", nor can the government meet its burden simply by asserting an adverse impact on the public. Justification under s. 1 is a process of demonstration, not intuition or automatic deference to the government's assertion of risk. ${ }^{96}$

I think the Supreme Court is right that Canada failed to establish that a total ban on assisted dying "was necessary in order to substantially meet the government's objectives." Nor, I think, would a parallel argument justify banning assisted dying for the mentally ill. But I disagree that the fear Canada advanced here is merely "theoretical or speculative." Physicians are human, systems of safeguards are not infallible, and errors and oversights will occur. Again, this is not far-fetched, and it could be easily demonstrated by adverting to evidence of medical errors, misdiagnoses, and so on. These things happen in the context of medical care, and there is no reason to think that matters of assisted dying will be exempted, and the Supreme Court glosses this over. But this observation actually undermines the force of the government's appeal to risk in arguing against access for the vulnerable: there is literally no other context in medicine where we require zero risk. Every procedure, prescription, injection, and so on involves risk, no matter how slight. This is true of outcomes (for example, surgical procedures that have a risk of mortality), but is equally true of consent: for any medical procedure performed, there is some chance that the consenting patient is not fully competent. Some of those people may die prematurely as a result of the procedure they consent to. The problem is inherent to medicine, not just in the context of MAID, but we do not regard the fact of risk as a decisive reason to deny patients access to other procedures. The uncomfortable lesson is that we already adopt, to some extent, a posture of "acceptable losses" when it comes to medical consent. We should do so to the same extent for medical assistance in dying.

A further problem with the government's argument is that it neglects to properly engage with the issue that determines the question of legal access in the Canadian context, which involves the balancing of interests. The position that risk to the vulnerable is decisive against access to MAID relies on the suppressed premise that the interests of the vulnerable are more important or weigh more than the interests of those who genuinely and rationally desire MAID, and that the legal scales should fall in their favour. But (I take it) a proposition underlying the rationale for access to MAID is that the lives of the people who genuinely and 
rationally desire it are sources of disutility to them, so much so that they reasonably regard themselves worse off alive than dead. In other words, their genuine interest lies in no longer being alive. The incompatibility of this interest with others' genuine (but potentially threatened) interest in living would support a total ban on MAID only if we assume that the interests of the vulnerable are more important, that is, that the interests of the vulnerable outweigh those of rational seekers of assisted dying. Without the suppressed premise giving priority to the vulnerable, the fact that we may not be able to completely reconcile these respective interests does not decide the question of access.

An underlying issue here involves an unfortunate feature of the MAID debate, namely that the relevant conflict among interests is usually mischaracterized. The debate over access to MAID almost always proceeds from a perceived conflict between the autonomy interest of individuals who desire assisted dying on the one hand, and the life interest, or well-being, of vulnerable individuals on the other hand.$^{97}$ But this is actually an error. The interestbalancing equation is about more than autonomy versus well-being: it is about how to reconcile the well-being of those whose interests would be served by an assisted death, and the well-being of the decisionally vulnerable who might be threatened by permitting or expanding access to assisted dying. For most people, death is and will always remain a threat to their well-being until the end of their natural lives, but for others, continuing to live is a serious threat to them because of the harm it subjects them to. ${ }^{98}$ Those who advance the "no acceptable losses" objection need an argument that the imperative to prevent premature deaths outweighs the imperative to help those with a rational wish to die, even when the normative force of both imperatives derives from the moral value of advancing and preserving human well-being. ${ }^{99}$

A more convincing way to put this is to acknowledge that the individuals who genuinely and rationally desire MAID, but are denied it, are another class of vulnerable people vulnerable in the sense that they are subject, against their will, to continue to live a life they have good reasons for wishing to exit. In that sense, their interests - their well-being — is threatened by the prohibition against MAID. ${ }^{100}$ Consider also that those whose interest lies in an assisted death, including some decisionally vulnerable people, will be subject to external pressure and manipulation (social, familial, and so on) to stay alive against their rational will. Thus, their interests and autonomy are threatened in a way parallel to those whose genuine interest lies in continuing to live. The argument that protection of one class of vulnerable people should be the only, or even primary concern overlooks this: other interests matter as well, and if we accept the idea that in opting for an early death an individual is not necessarily making a mistake, then we ought to show regard for their decision. None of this is to suggest that people should not be protected from opting for MAID in moments of weakness or from the threat of external pressure, but it does suggest

The preamble of Bill C-14, supra note 2, states the conflict in exactly those terms: "permitting access to medical assistance in dying for competent adults whose deaths are reasonably foreseeable strikes the most appropriate balance between the autonomy of persons who seek medical assistance in dying, on one hand, and the interests of vulnerable persons in need of protection ... on the other." As Maier-Clayton saw it: "[n]on-existence is better than this" (quoted in Xing, supra note 57). This is the answer to Kim and Lemmens' demand for an explanation of why expanding access to MAID for individuals with mental illness is important enough that we should be "willing to tolerate a number of potentially avoidable premature deaths" (Kim \& Lemmens, supra note 93 at E338).

This crosses the non-maleficence line just as intelligibly as subjecting certain others to the risk of premature death. 
that we should care just as much about the people threatened by a total ban. Objection 5 cannot establish what it sets out to do without a lot more philosophical legwork about why the disutility of a premature death is more important than the disutility of a life of suffering that is prolonged against an individual's will. Both sorts of patients are vulnerable to harm, and the law should acknowledge and reflect this. The proper scheme is one that strikes a balance between these interests; the current law, however, fails to fully satisfy that imperative.

\section{CONCLUSION}

None of the above objections to allowing assisted dying for mentally ill individuals appear to succeed. This suggests that the current ban on access to assisted dying for those with mental illness as their sole underlying condition is not justified and should be overturned. There may be more sophisticated objections available to opponents of MAID for the mentally ill, but it strikes me that it will be difficult to overcome the following considerations: first, if suffering can rationalize suicide in the first place, it can sometimes do so for individuals suffering from mental illness, just as it can for those suffering from a physical one. Second, the fact that mental illness does not usually impose a reasonably foreseeable death does not justify a ban; whether or not a person is dying, the suffering and its irremediability can justify ending one's life in rare, extreme cases. Third, the perception that individuals with mental illness are incapable of making an authentic, well-considered decision to end their lives is mistaken. Mental illness does not necessarily vitiate competent decision-making in regard to assisted death. Fourth, mental illness does not necessarily vitiate our ability to determine competence; just like in other cases of medical decisionmaking, including decisions about end-of-life care, capacity assessments can be performed and taken seriously, even for those with mental illness. Fifth, the observation that no system of safeguards under a regime of legal assisted dying can be one hundred percent effective in protecting decisionally vulnerable individuals is not decisive. Consider that the same is true of every risky or grave category of medical decision-making (for example, surgery, cessation of treatment, palliative sedation, and so on), and also that a ban threatens the valid interests of those who are denied the option of assisted dying. These interests must be taken seriously and balanced against the risks to others. Doing otherwise is unjust. 
[this page is intentionally blank] 